Rev. Bras. Saúde Prod. Anim., Salvador, v.15, n.2, p.289-296 abr./jun., 2014 http://www.rbspa.ufba.br ISSN 15199940

\title{
Vibrio parahaemolyticus em carcinicultura marinha
}

\author{
“Vibrio parahaemolyticus" in marine shrimp farming
}

\author{
MURATORI, Maria Christina Sanches Muratori ${ }^{1 *}$;VELOSO, Atyla Peeter Batista ${ }^{2}$; \\ COSTA, Amilton Paulo Raposo ${ }^{2}$; PEREIRA, Maria Marlúcia Gomes², GUIMARAES, \\ Cecília Melo Macedo ${ }^{3}$; CALVET, Rodrigo Maciel $^{3}$, SANTOS, Ygor Flávio de Moraes ${ }^{3}$; \\ CARDOSO FILHO, Francisco das Chagas ${ }^{3}$
}

\footnotetext{
${ }^{1}$ Universidade Federal do Piauí, Departamento de Morfofisiologia Veterinaria, Teresina, Piauí, Brasil.

${ }^{2}$ Médico Veterinário, Autônomo, Teresina, Piauí, Brasil.

${ }^{3}$ Universidade Federal do Piauí, Programa de Pós-Graduação em Ciência Animal, Teresina, Piauí, Brasil.

*Endereço para correspondência: chrismuratori@uol.com.br
}

\section{RESUMO}

Vibrio parahaemolyticus pode causar vibriose em camarão cultivado e também gastrenterites no consumidor. Neste trabalho foram verificadas as condições higiênico-sanitárias em camarões (Litopenaeus vannamei) e na água de viveiros de carcinicultura no litoral piauiense quanto a $V$. parahaemolyticus. Foram coletadas 148 amostras de água e 72 amostras de camarão em três fases de cultivo: pós-larva, juvenil e engorda em quatro propriedades. Foram transferidos $25 \mathrm{~g}$ de cada amostra para frasco contendo $225 \mathrm{~mL}$ de água peptonada com $3 \%$ de sal para o preparo da diluição $10^{-1}$, a partir dessa foram preparadas as diluições $10^{-2}$ e $10^{-3}$. Para o teste presuntivo, alíquotas de $1,0 \mathrm{~mL}$ dessas diluições foram semeadas em três tubos com caldo Horie Arabinose Violeta de Etila $\left(37^{\circ} \mathrm{C} / 24\right.$ horas $)$. Repicou-se para agar TCBS $\left(37^{\circ} \mathrm{C} / 24\right.$ horas). As colônias típicas foram semeadas em: agar motilidade sal, agar nutritivo sal, caldo peptonado sal e ágar TSI sal (incubados a $37^{\circ} \mathrm{C} / 24$ horas), testes bioquímicos: halofilismo $(0 ; 3 ; 6 ; 8$ e $10 \%)$, crescimento a $42^{\circ} \mathrm{C}$, teste de Kanagawa, prova de Hugh-Leifson, descarboxilação da lisisna e arginina e fermentação de manitol e sacarose. $V$. parahaemolyticus foi semelhante estatisticamente nas amostras de água e das fases pós-larva e engorda em todas as propriedades estuário e viveiros. Nas amostras de camarões também não houve diferença significativa estatística entre propriedades e fases de cultivo As águas do sistema produtivo e os camarões cultivados no litoral piauiense apresentam condições higiênicosanitárias satisfatórias quanto à enumeração de Vibrio parahaemolyticus.

Palavras-chave: camarão, Litopenaeus vannamei, qualidade de água

\section{SUMMARY}

Vibrio parahaemolyticus can cause vibriosis in shrimp, and also can cause gastroenteritis in consumers. Study the sanitary and hygienic conditions of shrimps (Litopenaeus vannamei) and water from ponds of shrimp farms of the coast of Piauí were evaluated for $V$. parahaemolyticus. 148 samples of water and 72 samples of shrimp were collected in three different farming stages (postlarvae, juvenile and growout) from four shrimp farms. $25 \mathrm{~g}$ of each sample was transferred to a flask containing $225 \mathrm{~mL}$ of peptone water with $3 \%$ of salt for the preparation of the $10^{-1}$ dilution, from which the $10^{-2}$ and $10^{-3}$ dilutions were prepared. For the presumptive test aliquotes of $1,0 \mathrm{~mL}$ of these dilutions were streaked in three Horie arabinose ethyl violet broth tubes $\left(37^{\circ} \mathrm{C} / 24\right.$ hours). They were restreaked TCBS agar $\left(37^{\circ} \mathrm{C} / 24\right.$ hours). The typical colonies were streaked: 
motility salt agar, nutrient salt agar, salt peptone broth and TSI salt agar $\left(37^{\circ} \mathrm{C} / 24\right.$ hours $)$ and then biochemical tests were performed: halofilic $(0 ; 3 ; 6 ; 8$ and $10 \%)$, growth at $42^{\circ} \mathrm{C}$, Kanagawa test, Hugh-Leifson test, lysine and arginine decarboxylation and fermentation of mannitol and sucrose. The presence of $V$. parahaemolyticus was statistically similar in samples of water and of postlarvae and grow out stages in all shrimp farms both in estuary and pond. In samples of shrimp there was no statistical difference among shrimp farms and farming stages. The water from the productive system and the shrimp raised in the cost of Piauí has satisfactory hygienic and sanitary conditions to Vibrio parahaemolyticus count.

Keywords: Litopenaeus vannamei, shrimp, water quality

\section{INTRODUÇÃO}

Mundialmente, o camarão marinho tem sido considerado como um importante recurso pesqueiro e nas regiões são capturadas espécies de alto valor econômico. Para atender a demanda crescente do mercado consumidor, a carcinicultura marinha foi incentivada pelaa exploração comercial do camarão branco do Pacífico (Litopenaeus vannamei) (MARTINS, 2003). No Brasil, as condições mais favoráveis para o cultivo ocorrem no litoral brasileiro entre o sul da Bahia ao norte do Pará (SCHOBER, 2002).

A carcinicultura é uma importante atividade econômica piauiense por gerar divisas e empregos diretos e indiretos para a população local. Nesta região existem propriedades carcinicultoras que produziram 3.079 toneladas de camarões em 2011, representando o quinto lugar na produção brasileira (ROCHA, 2013).

Quando ocorrem alterações na salinidade que afetam o sistema imunológico do $L$. vannamei, a vibriose pode ocorrer veiculada pelo Vibrio alginolyticus, $V$. harveyi e $V$. parahaemolyticus que habitam ambientes marinhos e estuarinos (LIMA, 2007). Por esse motivo a incidência de micro-organismos nos alimentos marinhos está relacionada à qualidade microbiológica da água em que os animais são cultivados (JAY et al., 2005).

Outro fato relevante quanto à presença de vibrios em camarões cultivados é que as espécies $V$. cholerae, $V$. parahaemolyticus, $V$. vulnificus, $V$. mimicus, $V$. alginolyticus, e $V$. hollisae quando veiculadas aos frutos do mar produtos destinados ao consumo, podem provocar desde gastrenterites (PEREIRA et al, 2004; LIMA, 2007; SEN et al., 2007; DEPAOLA \& JONES, 2013) a quadros de septicemia (LIGHTNER, 1996; QADRI et al. 2014). Por serem saprófitos, esses vibrios podem ser frequentemente isolados em crustáceos saudáveis (HUSS et al., 2004). Pelo fato dos Litopenaeus vannamei cultivados serem destinados ao consumo humano, deve ser avaliado os perigos potenciais da transmissão de víbrios para o consumidor, para prevenir possíveis riscos à saúde pública inerentes a carcinicultura. Pelo exposto, este trabalho objetivou verificar as condições higiênicosanitárias em camarões (Litopenaeus vannamei) e na água de viveiros de carcinicultura no litoral piauiense quanto à presença de Vibrio parahaemolyticus.

\section{MATERIAL E MÉTODOS}

Os carcinicultores piauienses classificam os viveiros conforme as fases de crescimento dos camarões. A primeira fase abrange de PL8 (Pós-larva com oito dias) até PL18 (Pós-larva com dezoito 
Rev. Bras. Saúde Prod. Anim., Salvador, v.15, n.2, p.289-296 abr./jun., 2014 http://www.rbspa.ufba.br ISSN 15199940

dias com peso 0,5 a $2,0 \mathrm{~g}$ ), a segunda de PL18 $(2,5$ a $6,6 \mathrm{~g})$ até os 90 dias e a terceira fase dos 90 aos 120 dias $(6,5$ a $12 \mathrm{~g}$ ).

As amostras de água e de camarões foram coletadas em quatro das 14 propriedades existentes no litoral piauiense (delimitado entre $2^{\circ} 55^{\prime} 51,39^{\prime}$ 'S $-22^{\circ} 58^{\prime} 04,31^{\prime}$ 'S a

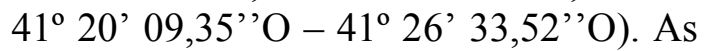
propriedades foram selecionadas por sorteio e identificadas para fins de pesquisas como "A", "B", "C" e "D". Para amostragem por propriedade foi sorteado um viveiro para cada uma das três fases de cultivo (pós-larva - fase I, juvenil - fase II e engorda - fase III) sendo realizadas seis coletas, totalizando 72 amostras $100 \mathrm{~g}$ de camarão. O esquema fatorial para amostras de camarão foi: $4 \mathrm{x}$ 3 (quatro fazendas e três fases do ciclo de cultivo: pós-larva, juvenil e engorda), com seis repetições representadas por coletas em dias diferentes. Os camarões foram despescados com tarrafa, em seguida transferidos para sacos plásticos esterilizados (Whirl-Park $\mathrm{B}_{\mathbb{B}}$ ) para transporte.

Nas quatro propriedades foram coletadas amostras $100 \mathrm{~mL}$ de água diretamente do estuário no local de captação (grupo controle) e no afluente e efluente dos três viveiros que foram sorteados para coleta de camarões. Essas coletas foram repetidas seis vezes totalizando 148 amostras de água. Estas amostras foram coletadas em sacos plásticos esterilizados $\left(\right.$ Whirl-Park $\left._{\mathbb{B}}\right)$ para transporte até o laboratório.

Após a coleta, as amostras de camarão e de água foram conduzidas em recipiente isotérmico contendo gelo reciclável ao Laboratório de Controle Microbiológico de Alimentos, do Núcleo de Estudos, Pesquisa e Processamento de Alimentos do Centro de Ciências Agrárias, da
Universidade Federal do Piauí para as análises.

$\mathrm{Na}$ sequência, por cada fase eram pesados camarões até que fossem obtidos $25 \mathrm{~g}$ diretamente em frascos contendo $225 \mathrm{~mL}$ de solução salina a 3,0\%. Em seguida, foram retiradas alíquotas de $1,0 \mathrm{~mL}$ para o preparo de duas diluições decimais (até $10^{-3}$ ). O mesmo procedimento de diluição foi realizado com as amostras de água, das quais foram retiradas alíquotas de $25 \mathrm{~mL}$.

Para a enumeração de $V$. parahaemolyticus foi utilizada a metodologia recomendada por DePaola \& Jones (2013). Por amostras, das três diluições utilizadas alíquotas de $1,0 \mathrm{~mL}$ foram transferidas para três tubos contendo caldo Horie Arabinose Violeta de Etila (HAEB) que foram incubados em estufa a $37^{\circ} \mathrm{C}$ por 24 horas para o teste presuntivo. Dos tubos de HAEB que apresentaram turvação foram repicados em agar tiossulfato citrato sacarose sais biliares (TCBS) que foram incubados a $35^{\circ} \mathrm{C}$ por 24 horas. Em seguida, as colônias características foram transferidas para agar motilidade sal, agar nutritivo sal, caldo peptonado sal e ágar TSI sal, todos incubados a $35^{\circ} \mathrm{C}$ por 24 horas. Decorrido este período os seguintes testes bioquímicos foram realizados: teste de halofilismo $(0 ; 3 ; 6 ; 8$ e $10 \%)$, crescimento a $42^{\circ} \mathrm{C}$, teste de Kanagawa, prova de Hugh-Leifson, descarboxilação da lisisna e arginina, e fermentação de carbo-hidratos (manitol e sacarose). Os resultados foram expressos em número mais provável por grama $(\mathrm{NMP} / \mathrm{mL})$.

Após a obtenção dos resultados foi realizada a análise de variância e aplicação do teste SNK para comparação das médias. Para efeito estatístico os resultados foram transformados em 
Rev. Bras. Saúde Prod. Anim., Salvador, v.15, n.2, p.289-296 abr./jun., 2014 http://www.rbspa.ufba.br ISSN 15199940

$\log _{10}(\mathrm{x}+1)$. O nível de significância utilizado em todos os testes foi $p<0,05$.

\section{RESULTADOS E DISCUSSÃO}

A enumeração de $V$. parahaemolyticus foi semelhante estatisticamente nas amostras de água das fases de pós-larva e engorda em todas as propriedades (Tabela 1). Na propriedade "C" as amostras da fase juvenil apresentaram maiores índices $(\mathrm{P}<0,05)$ de $V$. parahaemolyticus que as demais De um modo geral, as enumerações de $V$. parahaemolyticus obtidas nas amostras de estuário e viveiros foram semelhantes, $\mathrm{o}$ que indica que o manejo empregado nas propriedades não interferiu na quantidade da bactéria nas águas que eram lançadas no canal de drenagem.

Em trabalho realizado por Costa (2009) as espécies predominantes na água de captação e do viveiro foram $V$. parahaemolyticus e $V$. cholerae. Neste trabalho pesquisou-se somente $V$. parahaemolyticus, sendo encontrada em todas as amostras de água analisadas (Tabela 1), em quantidades próximas as obtidas por Serra et al. (2003), que encontrou uma variação de 1,04 a 5,04 de $\mathrm{NMP} / \mathrm{mL}$ de $V$. parahaemolyticus no rio Anil (MA), por Costa et. al. (2008) no estuário do rio Jaguaribe (CE) e por Rego et al. (2012) em Sirinhaém, Pernambuco. Entretanto, Mendes et al. (2009) encontraram Vibrio em quantidades superiores as observados na Tabela $1 \mathrm{em}$ fazendas carcinicultoras pernambucanas.

Tabela 1. Enumeração de Vibrio parahaemolyticus em amostras de águas que integram os sistemas de cultivo de camarões (Litopenaeus vannamei) no litoral piauiense

\begin{tabular}{|c|c|c|c|c|}
\hline \multirow{2}{*}{ Local da coleta } & \multicolumn{4}{|c|}{$\mathrm{NMP} / \mathrm{mL}$ de Vibrio parahaemolyticus por propriedade $\log _{10}{ }^{(\mathrm{x}+1)}$} \\
\hline & $\mathrm{A}$ & $\mathrm{B}$ & $\mathrm{C}$ & $\mathrm{D}$ \\
\hline Estuário & $1,2^{\mathrm{a}}$ & $1,4^{\mathrm{a}}$ & $1,7^{\mathrm{a}}$ & $1,0^{\mathrm{a}}$ \\
\hline Abastecimento pós-larva & $1,2^{\mathrm{a}}$ & $1,4^{\mathrm{a}}$ & $1,4 *$ & $1,1^{\mathrm{a}}$ \\
\hline Efluente pós-larva & $1,4^{\mathrm{a}}$ & $1,4^{\mathrm{a}}$ & $1,4^{*}$ & $1,2^{\mathrm{a}}$ \\
\hline Abastecimento juvenil & $1,4^{\mathrm{ab}}$ & $1,4^{\mathrm{ab}}$ & $2,5^{\mathrm{a}}$ & $1,0^{\mathrm{b}}$ \\
\hline Efluente juvenil & $1,2^{b}$ & $1,3^{\mathrm{b}}$ & $2,3^{\mathrm{a}}$ & $1,1^{\mathrm{b}}$ \\
\hline Abastecimento engorda & $1,1^{\mathrm{a}}$ & $1,4^{\mathrm{a}}$ & $2,4 *$ & $1,2^{\mathrm{a}}$ \\
\hline Efluente engorda & $1,2^{\mathrm{a}}$ & $1,4^{\mathrm{a}}$ & $2,3^{*}$ & $1,1^{\mathrm{a}}$ \\
\hline
\end{tabular}

${ }^{a, b}$ Letras iguais resultados semelhantes na mesma linha ou coluna $(\mathrm{P}<0,05)$.

* Nessa propriedade só foi possível coletar apenas uma amostra de água das fases de pós-larva e engorda. $\mathrm{NMP} / \mathrm{mL}=$ número mais provável por mililitros; $\log _{10}(\mathrm{x}+1)=$ números logaritmos na base 10 acrescidos de uma unidade.

As quantidades de $V$. parahaemolyticus nas amostras de camarões analisadas foram semelhantes estatisticamente entre as propriedades e entre as fases de cultivos (Tabela 2), quantidades de $V$. parahaemolyticus superiores foram observadas por Mendes et al. (2009). Vaseeharam \& Ramasamy (2003), citam que a presença de V.parahaemolyticus em corpos aquáticos destinados a cultura de 
Rev. Bras. Saúde Prod. Anim., Salvador, v.15, n.2, p.289-296 abr./jun., 2014 http://www.rbspa.ufba.br ISSN 15199940

camarões é preocupante uma vez que algumas cepas podem provocar doenças nos peneídeos. Além disso, a incidência dessa espécie de Vibrio na água pode contaminar a fauna e provocar doenças em humanos quando do consumo de alimentos contaminados.

Tabela 2. Enumeração de Vibrio parahaemolyticus em amostras de camarões (Litopenaeus vannamei) em sistemas de cultivo de camarões no litoral piauiense

\begin{tabular}{lcccc}
\hline \multirow{2}{*}{ Fase de crescimento } & \multicolumn{4}{c}{$\mathrm{NMP} / \mathrm{mL}$ de Vibrio parahaemolyticus por propriedade $\log _{10}{ }^{(\mathrm{x}+1)}$} \\
\cline { 2 - 5 } & $\mathrm{A}$ & $\mathrm{B}$ & $\mathrm{C}$ & $\mathrm{D}$ \\
\hline Pós larval & $1,2^{\mathrm{a}}$ & $1,4^{\mathrm{a}}$ & $1,3^{*}$ & $1,1^{\mathrm{a}}$ \\
Juvenil & $1,2^{\mathrm{a}}$ & $1,4^{\mathrm{a}}$ & $1,3^{\mathrm{a}}$ & $1,1^{\mathrm{a}}$ \\
Engorda & $1,2^{\mathrm{a}}$ & $1,4^{\mathrm{a}}$ & $1,5^{*}$ & $1,2^{\mathrm{a}}$ \\
\hline
\end{tabular}

${ }^{a, b}$ Letras iguais resultados semelhantes na mesma linha $(\mathrm{P}<0,05)$.

*Nessa propriedade só foi possível coletar apenas uma amostra de água das fases de pós-larva e de engorda. $\mathrm{NMP} / \mathrm{mL}=$ número mais provável por mililitros; $\log _{10}{ }^{(\mathrm{x}+1)}=$ números logaritmos na base 10 acrescidos de uma unidade.

A legislação vigente (BRASIL, 2001) não estabelece parâmetros para $V$. parahaemolyticus para camarões, entretanto, os resultados obtidos para as amostras de camarão na fase de engorda estariam próprias para consumo quando comparados a legislação anterior que foi revogada (BRASIL, 1997). A incidência de espécies de Vibrio de importância sanitária em alimentos de origem marinha destinados ao consumo humano vem sendo evidenciada em bivalves marinhos no Brasil (PEREIRA et al., 2004; PEREIRA et al., 2007; RODRIGUES \& CARVALHO FILHO, 2012). Com o incremento da carcinicultura, pesquisadores têm avaliado também a importância dos víbrios quanto à sanidade dos camarões cultivados (MENDES et al, 2007, COSTA et al 2008; MENDES et al, 2009; COSTA et al, 2010; PAIVA-MAIA et al. 2013).

Em todas as fases de cultivo pesquisadas as quantidades de $V$. parahaemolyticus foram constantes (Tabela 2). Porém,
Costa et al. (2008) identificaram $V$. parahaemolyticus apenas nos camarões na fase final da engorda. Os víbrios podem se multiplicar em águas marinhas e apresentam hábitos saprófitos, podem ocorrer tanto na coluna d'água como na fauna, dependendo diretamente da temperatura do meio, sem que seja necessária a presença de hospedeiro (LIMA, 2007). Esse fato justifica a presença do $V$. parahaemolyticus tanto nas águas analisadas como nos camarões das diversas fases pesquisadas.

De um modo geral, os resultados obtidos indicaram que não houve diferença entre as amostras das águas de cultivo e as de camarão analisadas. Desta forma, a quantidade de $V$. parahaemolyticus nas águas de cultivo refletiu a que estava presente nos camarões despescados. Após despesca a quantidade de $V$. parahaemolyticus nos camarões pode aumentar caso haja exposição a temperaturas elevadas e utilização inadequada de cloro. 
Rev. Bras. Saúde Prod. Anim., Salvador, v.15, n.2, p.289-296 abr./jun., 2014 http://www.rbspa.ufba.br ISSN 15199940

As águas pertencentes ao sistema produtivo e os camarões cultivados no litoral piauiense apresentam condições higiênico-sanitárias satisfatórias quanto à enumeração de Vibrio parahaemolyticus.

A enumeração de $V$. parahaemolyticus nos camarões cultivados reflete as quantidades das águas do sistema produtivo.

\section{REFERÊNCIAS}

BRASIL. Portaria ${ }^{\circ} 451$ de 19 de setembro de 1997. Aprova o regulamento técnico princípios gerais para o estabelecimento de critérios e padrões microbiológicos para alimentos e seus anexos I, II e III. Brasília. Disponível em:

$<$ http://www.ipef.br/legislacao/bdlegislac ao/detalhes.asp? $\mathrm{Id}=9643>$. Acesso em: 27 ago. 2009

BRASIL. Resolução RDC n ${ }^{\circ} 12$ de 02 de janeiro de 2001. Aprova o Regulamento Técnico sobre padrões microbiológicos para alimentos. Disponível em:

$<$ http://e-

legis.anvisa.gov.br/leisref/public/showAct .php?id=144>. Acesso em: 27 ago. 2009.

COSTA, R.A.; VIEIRA, G.H.F.; SILVA, G.C.; VIEIRA, R.H.S.F.; SAMPAIO, S. Susceptibilidade "in vitro" a antimicrobianos de estirpes de Vibrio spp isoladas de camarões (Litopenaeus vannamei) e de água de criação destes animais provenientes de uma fazenda de camarões no Ceará Nota prévia.

Brazilian Journal of Veterinary

Research and Animal Science, v.45, n.6, p.458-462, 2008.
COSTA, R.A.; VIEIRA, G.H.F.; VIEIRA, R.H.S.F.; SAMPAIO, S.S. Vibrio em amostras de água de viveiros de cultivo do camarão marinho Litopenaeus vannamei, no Ceará-Brasil. Atlântica, v.31, n.2, p.177-182, 2009.

COSTA, S.W.; VICENTE, L.R.M.; SOUZA, T.M.; ANDREATTA, E.R.; MARQUES, M.R. F. Parâmetros de cultivo e a enfermidade da mancha-branca em fazendas de camarões de Santa Catarina. Pesquisa Agropecuária Brasileira, v.45, n.12, p.1521-1530, 2010.

DEPAOLA, A; JONES, J.L. Vibrio. In: VANDERZANT, C.; SPLITTSTOESSER, D.F. APHA: Compendium of methods for the microbiological examination of foods. 4.ed. Washington: American Public Health Association, 2013. 1219p.

HUSS, H.H.; ABABOUCH, L.; GRAM, L. Assessment and management of seafood safety and quality. Rome: Food and Agriculture Organization of the United Nation, 2004. (Fisheries Technical Paper, 44).

JAY, J.M. Microbiología moderna de los alimentos. 3.ed. Zaragoza: Acribia, 2005.

LIGHTNER, D.V. Diseases of penaeid shrimp. In: MCVEY, J.P. (Ed.) Handbook of Mariculture. 2nd ed. Boca Raton: CRC Press, 1996. p.393-486. (Crustacean Aquaculture, 1).

LIMA, A.S. Vibrio em camarão e na água de três fazendas de carcinicultura do Ceará. 2007. 120p. Dissertação (Mestrado em Ciências Marinhas e Tropicais) Universidade Federal do Ceará, Fortaleza. 
Rev. Bras. Saúde Prod. Anim., Salvador, v.15, n.2, p.289-296 abr./jun., 2014 http://www.rbspa.ufba.br ISSN 15199940

MARTINS, P.C.C. Influência das condições ambientais e das técnicas do manejo de produção sobre a ocorrência de enfermidades no cultivo de camarão marinho Litopenaeus vannamei, no Estado do Ceará. São Paulo: UFSC: Programa de Pós-graduação em Ecologia e Recursos Naturais, p. 117, 2003.

MENDES, E.S.; BARRETO, A.C.G.; GÓES, L.M.N.B.; GUIMARÃES, J.M.; NASCIMENTO, D.L.; DINIZ FILHO, R.S.; MENDES, P.P. Avaliação do exame a fresco em camarões marinhos Litopenaeus vannamei (Boone, 1931) associado à contagem e identificação de Vibrio spp. em água de cultivo. Medicina Veterinária, v.1, n.2, p.7-15, 2007.

MENDES, E.S.; LIRA, S.F.; GÓES, L.M.N.B.; DOURADO, J.; MENDES, P.P. ALVES, C.A.B. Vibrio spp. isolados de camarão e água de cultivo de fazenda marinha em Pernambuco. Ciência Animal Brasileira, v.10, n.4, p.11911199, 2009.

PAIVA-MAIA, E.; ALVES-MODESTO, G.; OTAVIO-BRITO, L.; OLIVERA, A.; VASCONCELOS-GESTEIRA, T.C.

Effect of a commercial probiotic on bacterial and phytoplankton concentration in intensive shrimp farming (Litopenaeus vannamei) recirculation systems. Latin American Journal of Aquatic Research, v.41, n.1, p.126-137, 2013.

PEREIRA, C.R.; VIANA, C.M.; RODRIGUES, D. P.Vibrio parahaemolyticus produtores de urease isolados a partir de ostras (Crassostrea rizophorae) coletadas in natura em restaurantes e mexilhões (perna perna) de banco natural. Ciência e Tecnologia de Alimentos, v.24, n.4, p.591-595, 2004.
PEREIRA, C.S; POSSAS, C.A; VIANA, C.M.; RODRIGUES, D.P. Vibrio spp. isolados a partir de mexilhões (Perna perna) e pré-cozidos de Estação Experimental de Cultivo, Rio de Janeiro, RJ, Brasil. Ciência e Tecnologia de Alimentos, v.27, n.2, p.387-390, 2007.

QADRI, F.; ALAM, M.S.;

NISHIBUCHI, M.; RAHMAN, T.A.; HAQUE, N.; CHISTI, J.; KONDO, S.; SUGIYAMA, J.; BHUIYAN, N.A.; MATHAN, M.M.; SACK, D.A.; NAIR, G.B. Adaptive and Inflammatory Immune Responsesin Patients Infected with Strains of Vibrio parahaemolyticus. JID, v.2003, n.187, p.1085-1096, 2014.

REGO, M.; SILVA, E.; CALAZANS, N.; VOGELEY, J.; NERY, R.; SOARES, R.; PEIXOTO, S. Utilização de probiótico e antibiótico no cultivo de pós-larvas do camarão branco Litopenaeus vannamei, Atlântica, v.2, n.34, p.137-143, 2012.

ROCHA, I.P. Carcinicultura: realidade mundial, perspectivas e entraves confrontados pelo Brasil. Revista ABCC, edição especial, p.14-44, maio, 2013. Disponível em $<$ http://issuu.com/tfds1/docs/abcc_maio_ 2013_gr>. Acesso em: 7 abr. 2014.

RODRIGUES, L.A.P.; CARVALHO FILHO, C.D. Avaliação da ocorrência de Vibrio parahaemolyticus em ostras (Crassostrea rhizophorae) cultivadas na Baia de Todos os Santos. Revista Faz Ciência, v.15, n.20, p.197-207, 2012.

SCHOBER, J. Pesquisa impulsiona producao de camaroes em viveiros e mercado de trabalho regional. Ciência e Cultura, v.54, n.1, p.10- 11, 2002. 
Rev. Bras. Saúde Prod. Anim., Salvador, v.15, n.2, p.289-296 abr./jun., 2014 http://www.rbspa.ufba.br ISSN 15199940

SEN, B.; DUTTA, B.; CHATTERJEE, S.; BHATTACHARYA M.K.;. NANDY, R.K.; MUKHOPADHYAY, A.K.;

GANGOPADHYAY, D.N.;

BHATTACHARYA, S.K.;

RAMAMURTHY, T. The first outbreak

of acute diarrhea due to a pandemic strain of Vibrio parahaemolyticus $\mathrm{O} 3: \mathrm{K} 6$.

International Journal of Infections

Diseases, v.11, n.2, p.185-187, 2007.
SERRA, C.L.M.; CAVALCANTE, P.R.; ALVES, L.M.C.; NASCIMENTO, A.R.; DINIZ, S.C.C.S. Avaliação de parâmetros físico-químicos e pesquisa de Vibrio parahaemolyticus em águas do estuário do rio Anil (São Luís, Estado do Maranhão), Acta Scientiarum Biological Sciences, v.25, n.2, p.261-266, 2003.

VASEEHARAM, B.; RAMASAMY, P. Control of pathogenic Vibrio spp by Bacillus subtilis BT23 a possible probiotic treatment for black tiger shrimp P.monodon. Letters in Applied Microbiology, v.36, p.83-86, 2003.

Data de recebimento: 16/08/2013

Data de aprovação: 27/04/2014 